\title{
Effects of Rate of Drying, Life History Phase, and Ecotype on the Ability of the Moss Bryum Argenteum to Survive Desiccation Events and the Influence on Conservation and Selection of Material for Restoration
}

\author{
Joshua Lee Greenwood*, Lloyd R. Stark and Lindsay P. Chiquoine \\ School of Life Sciences, University of Nevada Las Vegas, Las Vegas, NV, United States
}

\section{OPEN ACCESS}

Edited by: Nicole Pietrasiak

New Mexico State University,

United States

Reviewed by:

Ricardo Cruz De Carvalho, University of Lisbon, Portugal

Peter Convey,

British Antarctic Survey (BAS),

United Kingdom

*Correspondence:

Joshua Lee Greenwood greenw33@unlv.nevada.edu

Specialty section:

This article was submitted to Biogeography and Macroecology,

a section of the journal

Frontiers in Ecology and Evolution

Received: 28 March 2019 Accepted: 27 September 2019

Published: 18 October 2019

Citation:

Greenwood JL, Stark LR and Chiquoine LP (2019) Effects of Rate of

Drying, Life History Phase, and Ecotype on the Ability of the Moss

Bryum Argenteum to Survive

Desiccation Events and the Influence on Conservation and Selection of

Material for Restoration.

Front. Ecol. Evol. 7:388.

doi: 10.3389/fevo.2019.00388
Desiccation stress is frequently experienced by the moss Bryum argenteum and can influence survival, propagation and niche selection. We attempted to disentangle the interacting factors of life history phase (five categories) and rate of desiccation (time allotted for induction of desiccation tolerance) for 13 ecotypes of B. argenteum. Using chlorophyll fluorescence as a stress index, we determined how these parameters influenced desiccation tolerance. Rate of drying and life phase significantly affected desiccation tolerance. The reaction norms of desiccation tolerance displayed by the 13 ecotypes showed a substantial degree of variation in phenotypic plasticity. We observed differences in survival and fluorescence between rapid and slow drying events in juveniles. These same drying applications did not produce as large of a response for adult shoots (which consistently displayed high values). Some juvenile and protonemal ecotypes, such as those from the southwest United States, possessed higher innate tolerance to rapid drying, and greater resilience compared to ecotypes sourced from mesic localities in the United States. These results show a complex nuanced response to desiccation with ecotypes displaying a range of responses to desiccation reflecting both inherently different capacities for tolerating desiccation as well as variation in capacity for phenotypic plasticity. Our results suggest that we should expect few short-term effects of climate change due to high desiccation tolerance of adult shoots, but significant adverse long-term effects on colony establishment due to low tolerance of protonema and juvenile shoots. Further, we would recommend that future studies using mosses for habitat restoration of aridlands consider the desiccation tolerance capacity of individual ecotypes used for cultivation and later re-introduction. Understanding how mosses respond to desiccation is essential to interpret ecological roles, habitat preferences, selective pressures, and responses to climate change, and to estimate the potential effects of climate changes on bryophyte species and populations.

Keywords: bryophyte, Bryum argenteum, chlorophyll fluorescence, desiccation, ecotype, life history, photosynthesis, rate of drying 


\section{INTRODUCTION}

Desiccation tolerance throughout an organism's life cycle has emerged as an important factor not only for considering an organism's response to environmental conditions (Proctor et al., 2007; Stark, 2017) but recently for laboratory and field studies which focus on using these organisms and their unique qualities to address conservation needs or in landscape-scale rehabilitation and restoration. Bryophytes, specifically mosses, are a growing focus for use in soil and landscape restoration (e.g., Antoninka et al., 2015, 2018; Condon and David, 2016; Cruz de Carvalho et al., 2018). A desiccation tolerant organism, such as a bryophyte, can equilibrate to $50 \%$ relative humidity (RH; i.e., -100 megapascals) and resume normal function when rehydrated (Wood, 2007). Particularly in disturbed arid and semi-arid environments and considering climate change, desiccation tolerance might be key to improving materials used in rehabilitation and restoration.

There are at least two factors required for understanding and predicting survival of an organism in response to desiccation: the organism's capacity for desiccation tolerance and its capacity to improve desiccation tolerance in response to environmental cues or previous exposure. The first of these is the inherent capacity of the organism to survive a desiccating event and is unaffected by external conditions or previous drying events. The second factor, phenotypic plasticity, is the degree to which an organism increases or decreases desiccation tolerance in response to environmental cues such as previous exposure to drying events. The capacity for phenotypic plasticity undergoes ontogenetic shifts as organisms develop such that plasticity might only be observable for specific time periods. Transitions such as this have been shown in vascular plants across life cycles (Mediavilla and Escudero, 2004). Recent research has demonstrated that desiccation tolerance in mosses is a variable and plastic trait for at least some species. For example, the terrestrial moss Physcomitrella patens and the aquatic moss Fontinalis antipyretica, were generally recognized as desiccation sensitive, but studies have demonstrated these mosses can withstand desiccation if a slow rate of drying is applied (Cruz de Carvalho et al., 2011, 2014; Greenwood and Stark, 2014).

Over the life cycle of an organism, the relative importance of abiotic (e.g., desiccation, intense light, heat, etc.) and biotic (e.g., intra and interspecific competition) factors can shift. For example, juvenile shoots appear to prioritize vertical growth to maximize energy gathering ability (e.g., shade competition) similar to vascular plants allocating energy between defense, reproduction, and growth over development (Bazzaz et al., 1987). Resource allocation shifts occur in sporophytes of Aloina ambigua, which switch from plastically desiccation tolerant to constitutively desiccation tolerant as sporophytes develop (Stark and Brinda, 2015).

Although phenotypic plasticity is the major means by which some organisms cope with environmental pressures, a phenotypically plastic response to desiccation would not be free of cost (Valladares et al., 2007). Generation of desiccation tolerant phenotypes would require associated maintenance and production costs for protein and sucrose formation believed necessary to develop a desiccation tolerant phenotype (DeWitt et al., 1998). Within this framework, phenotypic plasticity should be favored either in an organism which inhabits an environment that experiences shifting pressures or is variable (e.g., yearly or seasonal variation in precipitation), or in an organism that is deposited (e.g., moss spore rain; Miles and Longton, 1992) in a diversity of environments (Pigliucci, 2005).

Mosses occur in all terrestrial ecosystems, from equatorial jungles to temperate forests to deserts and even Antarctica, withstanding a diverse array of extreme environmental stresses. Mosses are often an essential component of terrestrial biocrust and play many beneficial roles such as ecosystem engineers, contributing to nutrient cycling, colonizing disturbed habitats, increasing soil stability, and aiding establishment of some seed plants (Brown and Bates, 1990; Belnap, 2006; Chaudhary et al., 2009; Weber et al., 2015). Some species can survive up to $120^{\circ} \mathrm{C}$ for 30 minutes (Stark et al., 2009), thousands of years beneath glacial ice sheets (La Farge et al., 2013; Roads et al., 2014), and decades of continuous desiccation at room temperature (Stark et al., 2016). Understanding how mosses respond to and tolerate desiccation can help guide conservation goals (i.e., identify vulnerable populations) and selection of materials for rehabilitation and restoration practices, particularly in advance of predicted climate changes. Land managers and restoration practitioners require guidance to develop appropriate survey techniques for identifying vulnerable populations, to develop strategies to conserve these populations (Tuba et al., 2011), and to identify potential materials (Zhao et al., 2016).

In this study we investigated the relationships between ecotypic variation, life history phase, and rate of drying upon desiccation tolerance in the species Bryum argenteum. Bryum argenteum makes an excellent study system due to its cosmopolitan distribution across arid, mesic, and urban settings. This species has one of the widest distributions of any plant and is found on all continents and in diverse habitats: hot and cold deserts, temperate and polar climates, and urban settings (Flora of North America Editorial Committee, 2014). Sexually dioecious, it is capable of short or long-distance dispersal via sexually generated spores, as well as clonal dispersal over short distances via bulbils. Phenotypic plasticity has been demonstrated previously in $B$. argenteum for thermal tolerance across ecotypes and may be reasonably expected for other physiological traits (He et al., 2016). A capacity for plasticity in response to environmental signals resulting in increased desiccation tolerance would allow a wider range of genotypes to survive the altered habitats, preserving genetic variation (Matesanz et al., 2010). This persistence would permit time either for a return to climatic norms, if they are relatively short-lived, or for the development of mutations and selection of more desiccation resistant forms, if effects are longer-lived.

The methods and design presented in this paper provide a roadmap for determining the physiological response to desiccation for populations of other mosses as well as describing how populations of a cosmopolitan moss can vary in physiological response. Specifically, we examined the relationships among five different life history phases with five rates of drying to an equilibrating 50\% RH for 13 ecotypes of 
B. argenteum. Similar to vegetative phenotypic phases, we used bulbils (shoot tissue that differentiates into discrete propagules), protonema, and juvenile $(<3 \mathrm{~mm})$, intermediate $(3-5 \mathrm{~mm})$, and adult ( $>5 \mathrm{~mm}$ long) shoots. Rate of drying influences the length of time which is required for an organism to reach a desiccated state at low internal water content. By examining a range of drying times (i.e., time spent at sub-turgor prior to desiccation), we can determine not just if a tissue is desiccation tolerant, but the time required for inducible desiccation tolerance to manifest. We applied these factors to specimens obtained from multiple source populations (ecotypes) in order to address to what degree ecotypes deviate in their capacity to tolerate desiccation among populations and how this might influence survival in different environments.

We hypothesized that all life phases would perform best with longer drying periods and that the effect of a slow vs. rapid dry would be more prominent in juvenile tissues and protonema. We hypothesized that evolutionary history influenced ecotypic variation and that samples from arid regions (southwest USA) would display greater desiccation tolerance and a shorter time required to induce desiccation tolerance compared to populations from mesic habitats (northwest and midAtlantic states USA). Finally, we hypothesized that protonema and juvenile forms would be most susceptible to desiccation, requiring longer timeframes for effective inducible desiccation tolerance compared to mature forms, which would indicate these phases are more vulnerable and less resilient to changes in environmental conditions.

\section{MATERIALS AND METHODS}

\section{Sample Collection}

Specimens were gathered from herbarium collections (collected between 1999 and 2009) from a range of North American (USA) habitats showing varied seasonal and yearly temperature and precipitation. Localities include Arizona (2 locations; male and female, $\sigma^{x} /$ ) $)$, California (3 locations; $\sigma^{\top} /$ ) $)$, Kentucky (2 locations; $\sigma^{x} /$ ) $)$, Nevada (1 location; $q$ only), New Mexico (1 location; $q$ only), Massachusetts [2 locations; $\left(\sigma^{x} / q\right)$, and Oregon (2 locations; $\sigma^{x} /$ ) ) (see Appendix)]. Selection of material from different locations does not necessarily indicate specimens are different genotypes. However, localities were selected with a high degree of geographic separation to reduce the likelihood of genotype replication.

\section{Selection of Material and Cultivation}

Wet-dry cycles experienced under field conditions combined with differential levels of resources and pre-existing injury and disease make assessment of desiccation tolerance or induciblydesiccation tolerant status difficult due to hardening (Stark et al., 2014). Induction of a hardening response has been observed in gametophytes of Crossidium crassinerve (Stark et al., 2014), the shoots of the gametophyte of Physcomitrella patens, and protonema of Funaria hygrometrica (Werner et al., 1991). For these reasons, we used lab cultivated samples under common growth conditions to assess desiccation tolerance and to avoid variation due to unknown field hardening effects. Previous research (e.g., Stark et al., 2014), estimated approximately 1 month of cultivation was necessary to remove field effects. For this experiment samples were kept in continuous cultivation for at least 1 year with a minimum of three subcultures before experimentation was begun.

We selected three major phenological classes: (1) bulbils, propagules specialized for roles as agents of dispersal; (2) protonema, which provide lateral expansion of moss colonies through and on surface soil; and (3) shoots, the major photosynthetic structures and bulk of gametophytic tissue. Shoots were additionally divided into three developmental classes based on height ( $<3 \mathrm{~mm}$, juvenile; $3-5 \mathrm{~mm}$, intermediate; and $>5 \mathrm{~mm}$, adult).

Shoots were isolated and cultivated following Greenwood and Stark (2014) to remove habitat-acquired acclimation. Bulbils were collected from shoots of stock cultures growing in sand substrate. Protonema required unique cultivation as they adhere to substrate, making isolation difficult without destroying tissue. Protonema, therefore, were cultivated in a liquid media of $30 \%$ Hoagland's solution (Hoagland and Arnon, 1950). To develop protonemal cultures, test tubes $(16 \times 100 \mathrm{~mm})$ were inoculated with a single leaf from stock cultures. Protonemata were grown at $24^{\circ} \mathrm{C}$ with constant light $\left(59 \mu \mathrm{mol} \mathrm{m} \mathrm{m}^{-2} \mathrm{~s}^{-1}\right.$ PAR; photosynthetically active radiation). Tubes were sealed with parafilm and inverted twice daily to increase gas exchange.

\section{Sample Material Preparation}

For each ecotype, shoots were selected when they reached target lengths (juvenile, $<3 \mathrm{~mm}$; intermediate, $3-5 \mathrm{~mm}$; and mature, $>5 \mathrm{~mm}$ ), with five shoots used per sample unit. For protonema, material was collected from liquid stock to produce all sample units. Due to the small size of individual bulbils, 50 bulbils collected from sand substrate stock cultures were used per sample unit. All tissue material was blotted between two sheets of Whatman \#1 filter paper to remove excess superficial water before placing the tissue on top of an artificial substrate (Whatman \#1 filter paper) within 35-mm diameter Petri dishes.

\section{Stress Application}

The rate of drying was controlled by adding specific volumes of sterilized water to the filter paper before the addition of tissue to the dish following Greenwood and Stark (2014). Volumes were selected to attempt to encompass a variation in drying time that are representative of xeric and semi-xeric locations such that responses for individual habitats could be extrapolated if standard rainfall patterns are known for the area. Volumes for rate of drying included: $0 \mu \mathrm{L}$ with no lid ( $<20 \mathrm{~min}), 0 \mu \mathrm{L}$ lidded (<30 min), $12.5 \mu \mathrm{L}$ lidded ( $1 \mathrm{~h}$ ), $25 \mu \mathrm{L}$ lidded $(4 \mathrm{~h})$, and $50 \mu \mathrm{L}$ lidded $(11 \mathrm{~h})$. Controlled rates of drying were carried out in an electric benchtop relative humidity chamber (Totech Super Dry, Totech, Tokyo, Japan) set to 50\% RH. The chamber was located inside of an environmental control room (R.W. Smith and Co., San Diego, CA, USA) set to $20^{\circ} \mathrm{C}$ and $50 \% \mathrm{RH}$. Samples were stored for an additional $24 \mathrm{~h}$ at $50 \% \mathrm{RH}$ after equilibration to ensure all material was dried to equilibration. Verification of dry material follows procedures in Greenwood and Stark (2014). Unstressed shoots with no prior drying events 
obtained from the existing stock cultures served as controls. All treatment combinations, ecotype $\times$ life phase $\times$ rate of drying, were replicated five times.

\section{Chlorophyll Fluorescence as a Measure of Stress}

Following stress application, samples were rehydrated for $24 \mathrm{~h}$, transferred to leaf clips, and dark-adapted for $30 \mathrm{~min}$. Status of dark-adapted $\left(F_{\mathrm{v}} / F_{\mathrm{m}}\right)$ fluorescence, non-photochemical quenching (NPQ) and quantum efficiency of photosystem II ( $\Phi$ PSII) were determined with a pulse modulated chlorophyll fluorometer (FMS2, Hansatech Instruments Ltd, Norfolk, UK) using the saturation pulse method (Schreiber et al., 1995). $F_{\mathrm{v}} / F_{\mathrm{m}}$ is the maximum quantum efficiency of PSII under darkadapted conditions. Non-photochemical quenching is a method to dissipate excess excitation energy as heat, and a decrease in NPQ can indicate tissue damage. $\Phi$ PSII is the quantum efficiency of PSII electron transport in the light (Genty et al., 1989), with lower levels resulting from stress or damage.

\section{Data Analysis}

All 13 ecotypes, five life phases, and six rates of drying including controls resulted in a $13 \times 5 \times 6$ treatment design, or 390 total potential treatment combinations, $N=$ five per treatment, totaling 1,950 individual sample units. All fluorescence parameters were analyzed for significance of main treatments and all two-way and three-way treatment interactions using analysis of variance (ANOVA) in SPSS v.20 (IBM corp., Armonk, NY, USA), with life history phase, ecotype, and rate of drying set as fixed factors. For significant effects, post-hoc Tukey tests were applied to determine homogeneous subsets within main treatments and all significant interactions.

\section{RESULTS}

All three main treatments and all two-way and three-way interactions between treatment combinations were significant for all fluorescence $(P<0.001)$ parameters. Significance of interactions varied within and between rate of drying treatments, but results and trends were relatively consistent for fluorescence parameters. Rate of drying appeared to have had the greatest effect on fluorescence parameters, followed by life phase and ecotype (Figures 1A-D). For specific results per fluorescence parameter (see Supplemental Figures 1-3 and reaction norms on (Figures 4-8).

Rate of drying contributed strongly to the variability of fluorescence parameters within phases. Among life phases (Figure 1A) and among ecotypes (Figure 1D; Supplemental Figures 1-3) longer rates of drying increased fluorescence. Specifically, within ecotypes, there was an increase in fluorescence between a rapid dry and a 1 or $4 \mathrm{~h}$ drying time, although this was variable within ecotypes (Supplemental Figures 1-3). After a 1 or $4 \mathrm{~h}$ drying time for most ecotypes, increased drying time did not continue to significantly increase fluorescence. With increased drying time there were fewer differences among life phases (Figure 1A; reduced slope angle). The youngest shoots required $11 \mathrm{~h}$ to reach experimental control values but intermediate and mature shoots for many ecotypes demonstrated a strong response over a shorter drying time. However, within the time frames examined in this study, protonemal fluorescence values did not reach protonemal control fluorescence values and only achieved low mean values after an $11 \mathrm{~h}$ drying time. For example, $F_{\mathrm{v}} / F_{\mathrm{m}}$ only reached a mean $( \pm$ SE) of $0.368( \pm 0.025)$ after $11 \mathrm{~h}$. Overall, there was a strong trend toward greater recovery after rehydration with a longer rate of drying for most ecotypes within life phases.

Generally, for all life phases, fluorescence parameters improved with slower drying rates (Figure 1A). Significance between life phases varied within and between ecotype, although most of the variability was limited to the protonema and juvenile shoots across rate of drying treatments (Figures 1-5; Supplemental Figures 1-3). Protonema performed the poorest in response to desiccation stress, i.e., the lowest $F_{\mathrm{v}} / F_{\mathrm{m}}$ performance (mean \pm standard error; $0.355 \pm 0.01$ ), compared to shoots and bulbils (Figure 1C; Supplemental Figure 1). Protonema tended to remain vulnerable to damage across the rate of drying treatments (Figure 1A), except for three instances with ecotypes from the Southwest US (NM, CIMA, CA1, VF; Figure 4; Supplemental Figure 1). As shoots increase in age, mean fluorescence across all treatments and ecotypes increased: juveniles (0.635 \pm 0.009$)$; intermediates (0.697 \pm $0.007)$; adults $(0.702 \pm 0.006)$. Bulbils display the greatest fluorescence regardless of rate of drying (0.728 \pm 0.003$)$ (Figure 1C; Supplemental Figure 1) and tended to display the highest resistance to an extremely rapid dry (Figures 1A, 8; Supplemental Figure 1). Mean values of all phases responded positively to longer drying times, showing increased values approaching or equal to control values.

Ecotype grouped into four significantly homogeneous subsets (Figure 1D), with most of the signal driving these groups derived from the protonemal and juvenile shoot phases (Figures 4, 5; Supplemental Figure 1). Variation diminished over development in shoot tissues as mature shoots from all ecotypes displayed a high tolerance for desiccation (Figure 7). Likewise, bulbils also showed very low ecotypic variation and an extreme capacity for desiccation tolerance and did not show variation for phenotypic plasticity in response to rate of drying (Figure 8).

Reaction norms (ecotype by environment) for tissues showed some overall similarities as well as capacities unique to a subset of ecotypes. First, for all ecotypes examined, bulbils displayed a remarkably flat response to the rate of drying applied, exemplifying the importance of desiccation tolerance to this phase (Figure 8). For adult shoots many ecotypes performed well at all drying rates; however, AZ1, MA2, KY2, when dried more rapidly than $1 \mathrm{~h}$ performed far below most other ecotypes; if given an induction of $1 \mathrm{~h}$ or more they performed near the other ecotypes (Figure 7). With intermediate shoots most ecotypes required $1 \mathrm{~h}$ for development of a desiccation tolerance phenotype. Intermediate shoots from ecotypes of NM, CA2 had high values after only $30 \mathrm{~min}$, while conversely AZ1 was worse than all other ecotypes with lower values at most rates of drying and requiring a $4 \mathrm{~h}$ period before intermediate shoots showed values close to other ecotypes given a similar drying regime (Figure 6). Juvenile shoots required a longer rate 

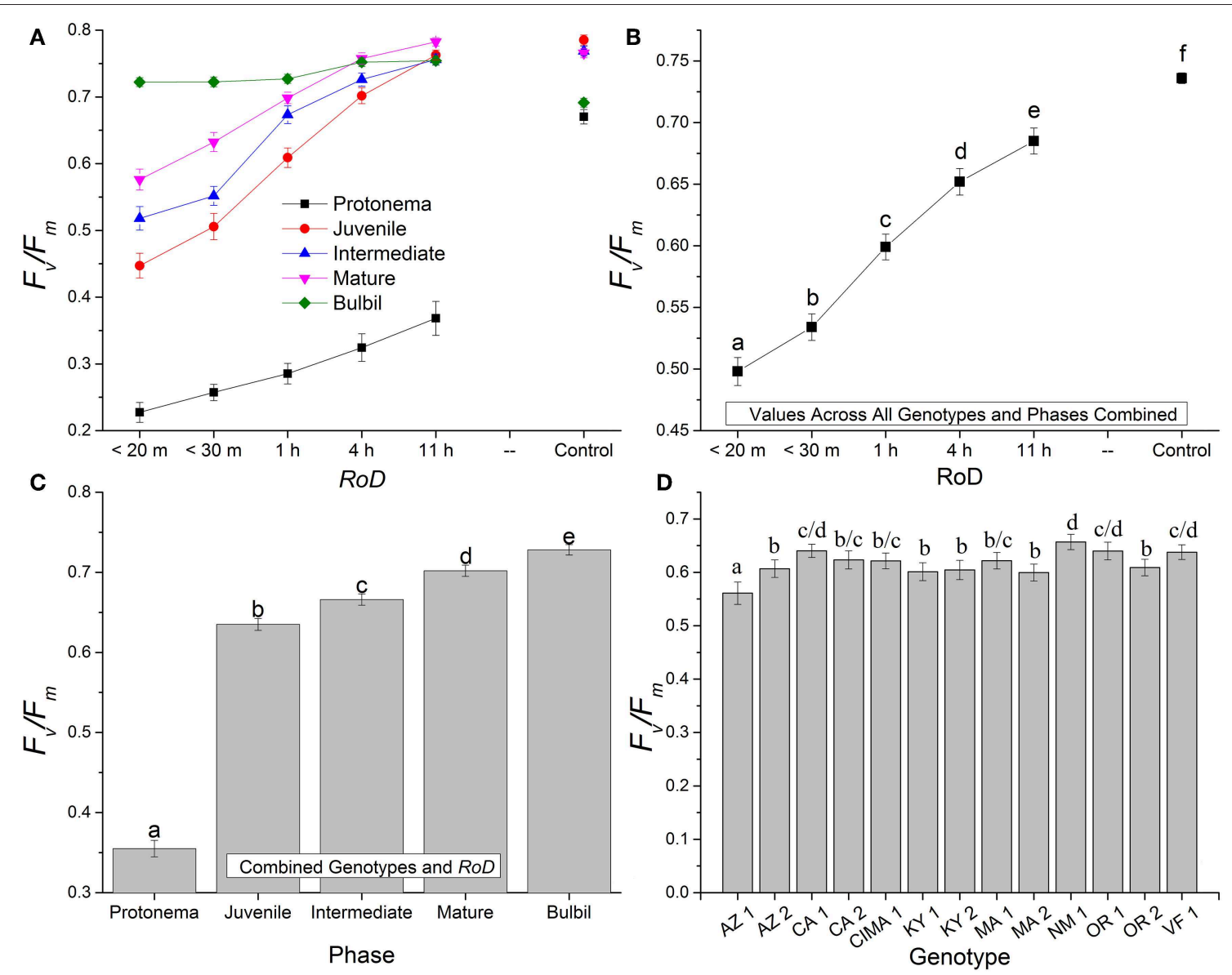

FIGURE 1 | Bryum argenteum $F_{\mathrm{v}} / F_{\mathrm{m}}$ response variables. Panel of images showing Bryum argenteum $F_{\mathrm{v}} / F_{\mathrm{m}}$ response variables $24 \mathrm{~h}$ post rehydration for the treatment combinations indicated, error bars represent \pm 1 SE, and lowercase letters represent homogeneous subsets established at an $\alpha$ of 0.05 . (A) Two-way interaction between rate of drying (RoD) and life phase ( $n=65)$, (B) Main effect of RoD among life phase and ecotypes combined $(n=390)$, (C) Main effect of life history phase among RoD and ecotype ( $n=390)$, (D) The effect of ecotype with all life phases and RoD treatments combined ( $n=150)$. RoD, Rate of Drying.

of drying to induce desiccation tolerance than other shoots on average with most ecotypes requiring one or more hours. Juvenile shoots of the AZ1 ecotype were again much less tolerant of desiccation than other ecotypes, requiring $4 \mathrm{~h}$ to induce a desiccation tolerance phenotype and displaying values consistently lower than all other ecotypes (Figure 5). Protonemal forms were the least likely to show a desiccation tolerance response of any kind in response to rate of drying, with only a handful showing signs of induction. Protonemal ecotypes of CIMA, VF, NM and CA1 were the exceptions with all showing induction after $11 \mathrm{~h}$ of drying, with NM and VF having reached control values. Protonema from NM showed a more rapid response than other ecotypes with strong induction achieved with only a $1 \mathrm{~h}$ slow dry, and control values reached by $4 \mathrm{~h}$ (Figure 4).

\section{DISCUSSION}

One might imagine two scenarios with respect to changing climate on moss distribution and species survival and how these factors relate to conservation efforts and selection of materials for restoration. In the first, a species is phenotypically plastic for desiccation tolerance, resulting in a relatively minor effect on moss residence or occupancy as a result of changes in climate conditions. A second scenario would be ecotypes that are highly adapted to their local environment possessing low phenotypic plasticity, such as we observed in protonema and juvenile shoots displaying ecotype-specific responses. We might hypothesize that a population will experience a loss in cover with a change in precipitation amount or frequency. Given these possibilities, we suggest land managers combating bryophyte cover loss to consider a pilot experiment to test the resilience of their local populations and select material that is more desiccation tolerant and resilient for restoration efforts.

Populations of $B$. argentum displayed different inherent capabilities for desiccation tolerance which are modulated by environmental factors, time spent at sub-turgor, ecotypic variation, life history phase, tissue type, and we expect a host of other environmental factors (e.g., temperature, rain frequency, solar irradiation, etc.), interacting to determine desiccation 

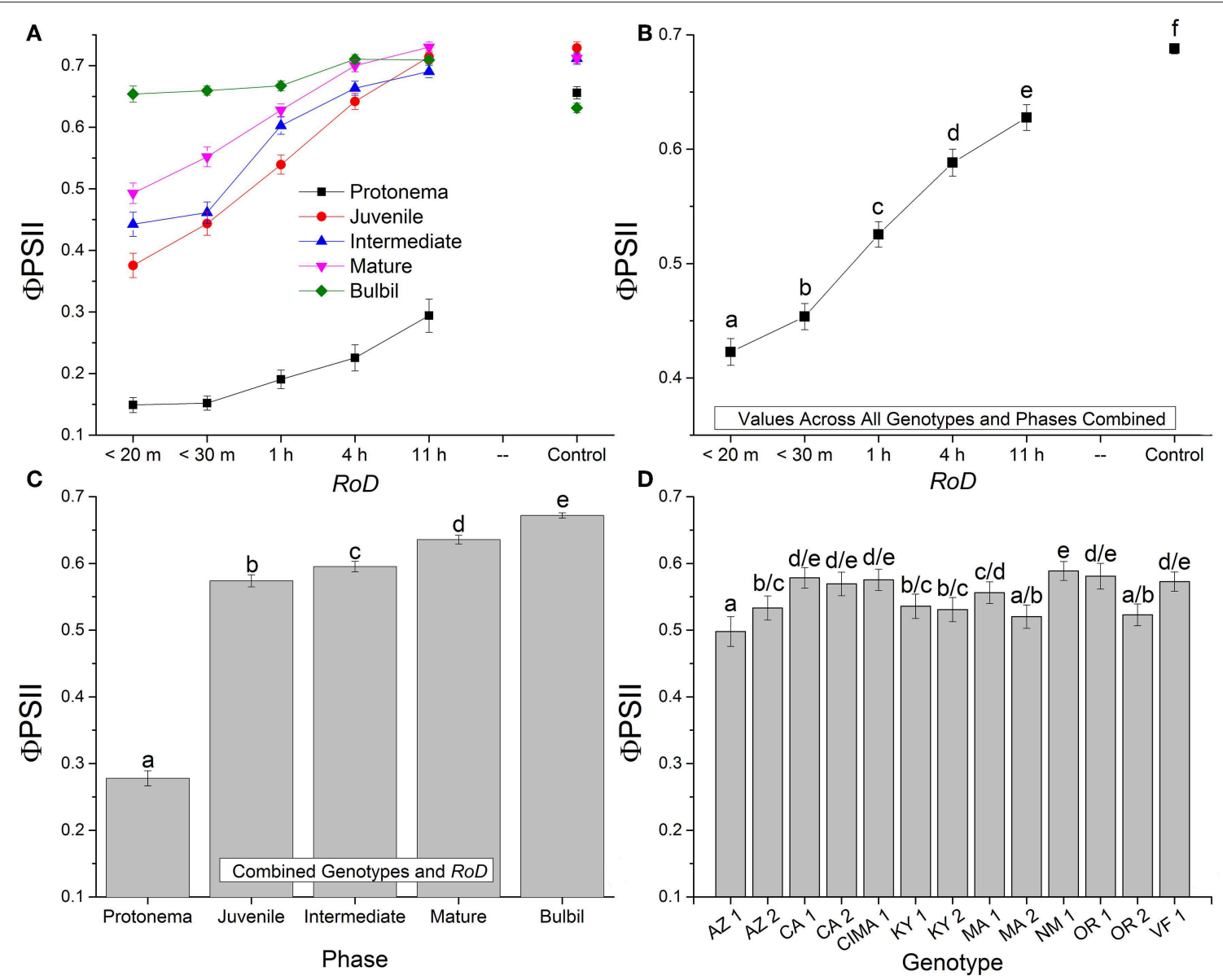

FIGURE 2 | Bryum argenteum $\Phi$ PSII Response variables. Panel of images showing Bryum argenteum $\Phi$ PSIl response variables $24 \mathrm{~h}$ post rehydration for the treatment combinations indicated, error bars represent \pm 1 SE, and lowercase letters represent homogeneous subsets established at an $\alpha$ of 0.05 . (A) Two-way interaction between rate of drying (RoD) and life phase $(n=65)$, (B) Main effect of RoD among life phase and ecotypes combined ( $n=390)$, (C) Main effect of life history phase among RoD and ecotype ( $n=390)$, (D) The effect of ecotype with all life phases and RoD treatments combined $(n=150)$. RoD, Rate of Drying.

tolerance. We uncovered significant differences in responses in every stage examined, showing a considerable and unexpected ontogenetic plasticity for desiccation tolerance: protonema were very resistant to induction, while bulbils exhibited extreme tolerance to desiccation at all drying rates examined. A highly variable capacity in phenotypic plasticity was found among ecotypes examined, especially within the protonemal and juvenile shoot phases. Although evidence in the literature suggests some moss species have morphological and physiological plasticity (e.g., Rincon and Grime, 1989; Hassel et al., 2005; Gao et al., 2015), few studies go beyond discussing desiccation tolerance within the context of plasticity (e.g., Stark, 2017) or measuring artificially-applied stressor responses across life history phases to test for potential phenotypic plastic responses to desiccation (but see Buryová and Shaw, 2005).

This study increases our understanding of factors related to desiccation (i.e., inducible desiccation tolerance, hardening, ecotypic, and life phase variation in desiccation tolerance) and enhances our ability to make reasonable predictions for how organisms will respond to climate changes. Predicting survival in a changing climate depends upon knowing if species have sufficient genetic variation for selection to act upon (Ghalambor et al., 2007; Matesanz et al., 2010; Shaw and Etterson, 2012). Species with high genetic variability possess a greater range of traits for selection to act upon, increasing the likelihood that some individuals in a population will be sufficiently adaptive to new climate regimes. However, if current genetic variation is insufficient for a population to adequately respond to rapid climate change, high levels of phenotypic plasticity alternatively act as a buffer against selection and allow for a wider range of existing genotypes to persist until sexual recombination can provide more competitive combinations of alleles and chromosomes (Ghalambor et al., 2007; Matesanz et al., 2010; Shaw and Etterson, 2012).

Although we observed variation in desiccation tolerance and phenotypic plasticity in desiccation response, at least for some ecotypes, this could be counter balanced by low rates of sexual reproduction and low occurrence of male sex expression in xeric 

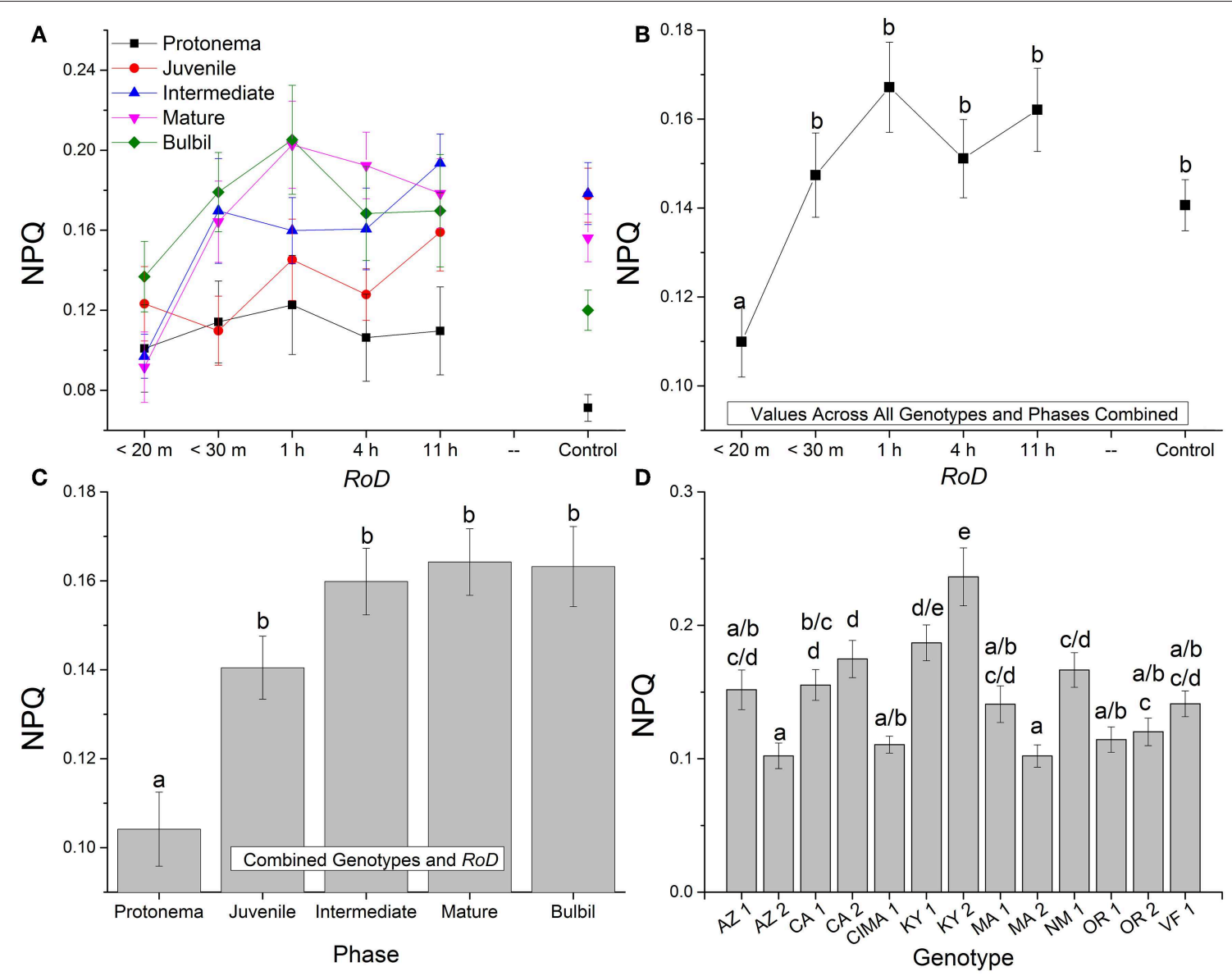

FIGURE 3 | Bryum argenteum NPQ response variables. Panel of images showing Bryum argenteum NPQ response variables $24 \mathrm{~h}$ post rehydration for the treatment combinations indicated, error bars represent $\pm 1 \mathrm{SE}$, and lowercase letters represent homogeneous subsets established at an $\alpha$ of 0.05 . (A) Two-way interaction between rate of drying (RoD) and life phase $(n=65)$, (B) Main effect of RoD among life phase and ecotypes combined $(n=390)$, (C) Main effect of life history phase among RoD and ecotype ( $n=390)$, (D) The effect of ecotype with all life phases and RoD treatments combined $(n=150)$. RoD, Rate of Drying.

habitats (Stark et al., 2010). The effects of clonal propagation combined with strong selective pressure for desiccation tolerant phenotypes will likely lead to a loss of genetic variability over the short term in xeric habitats as hardier clonal forms expand into locations previously occupied by less desiccation tolerant forms. The cosmopolitan distribution of $B$. argentum, as well as its high capacity for long distance spore dispersal, over longer time frames should re-introduce genetic variation to xeric habitats. However, many other xeric species with restricted and or patchy distribution combined with potentially lower capacity for spore dispersal would have a less optimistic long-term outlook as they would not have a large source of genetic material preserved in other habitats to re-introduce into the xeric localities. We do, however, hypothesize that some species with a high capacity for dispersal are poised to act akin to an invasive species in the event of climate change, such as those like $B$. argenteum in population size, dispersal capacity, and a wide habitat preference.

Bryophytes have two major methods for dispersal: vegetative propagules (e.g., bulbils) and spores. Vegetative propagules have greater mass and density and contribute to short distance dispersal and maintenance of populations. Spores contribute to long distance dispersal across landscapes (Patiño and Vanderpoorten, 2018). Bryophytes are thought to be efficient spore-dispersing organisms, with 100 kilometers suggested as a likely distance a spore could travel (Vanderpoorten et al., 2019). Bryophytes have relatively low rates of endemism compared to seed plants, and species composition patterns match more closely with wind connectivity patterns than geographic proximity (Patiño and Vanderpoorten, 2018). With this in mind, major factors controlling dispersal ability appear to be a combination of spore mass, density, surface area, and ornamentation (Zanatta et al., 2016). A world-wide spore rain combined with the ability to succeed in many habitat types and rapid environmental shifts could result in a rapid spread of newly invasive organisms.

\section{Desiccation Tolerance Along a Continuum of Life History Phases}

The tissues examined in this study showed a wider degree of responses than expected, but all tissues responded in a manner logically consistent with their roles. Protonema are 


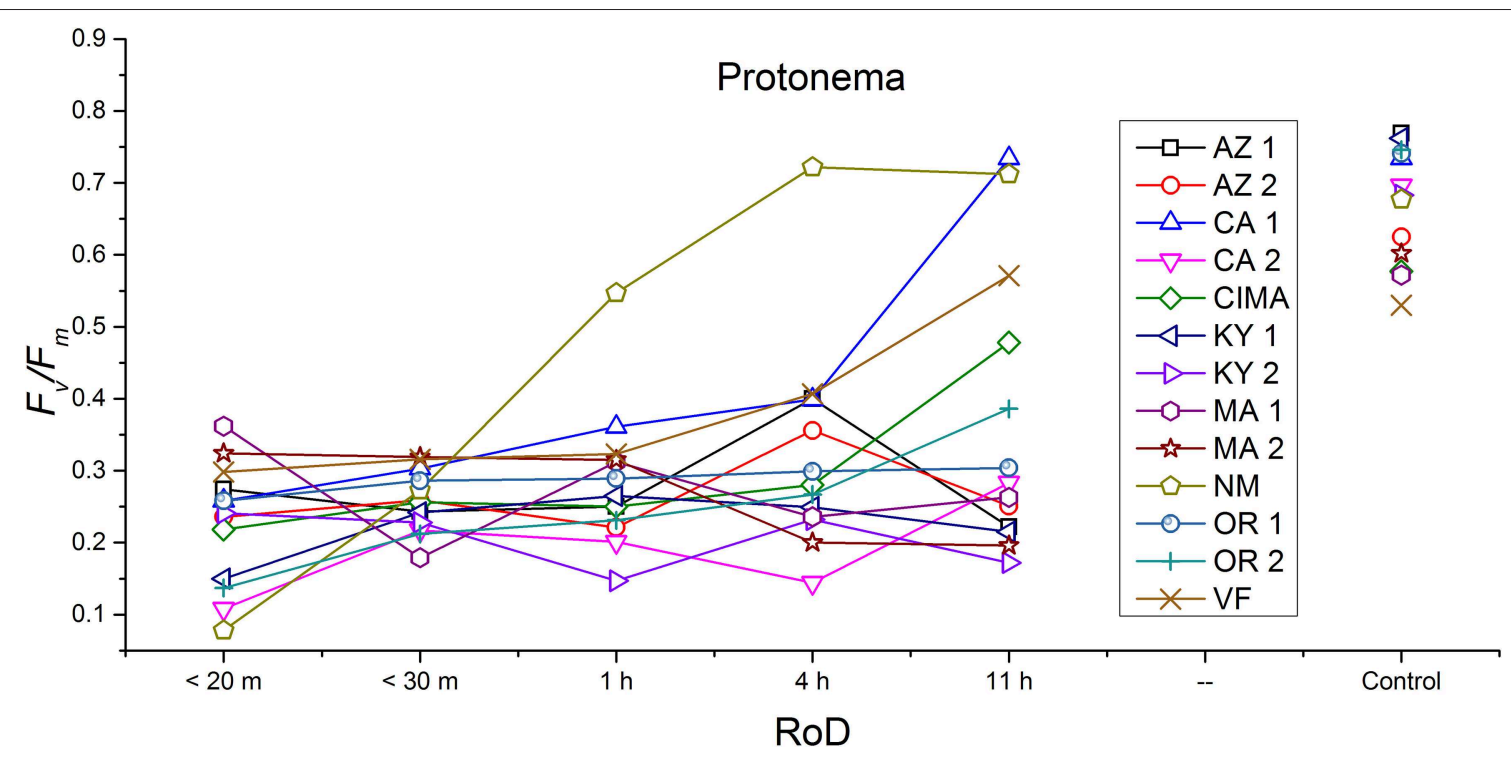

FIGURE 4 | Reaction norms for protonema from 13 ecotypes exposed to five rates of drying (RoD) $24 \mathrm{~h}$ post rehydration.

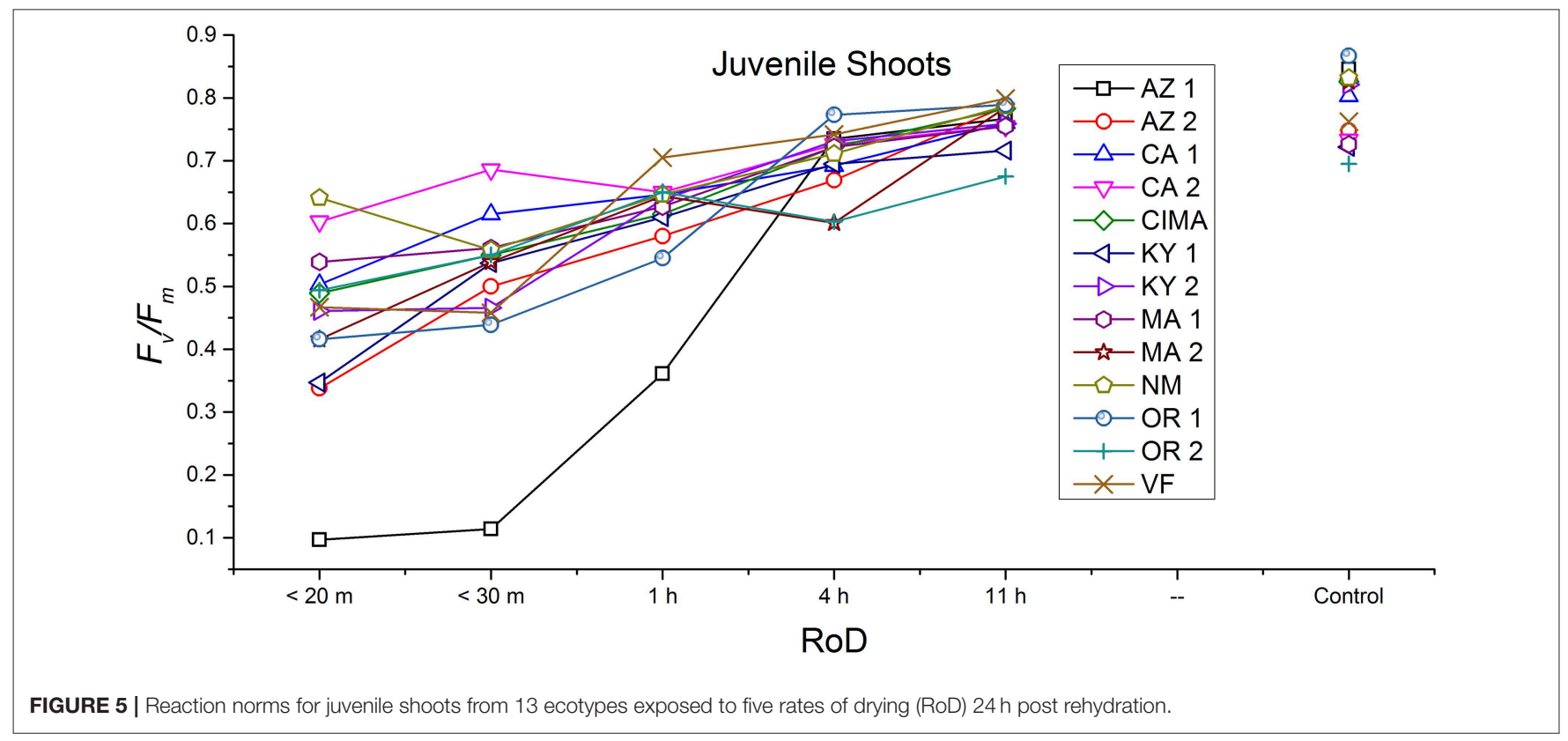

most sensitive. This sensitivity may be mitigated in nature as the intrinsic properties of soil result in slower drying rates than tissues aboveground, providing longer drying periods and, thus, more time for plasticity induction. Bulbils lack protective functions of colonial patch dynamics (e.g., slowing of water loss due to dense cushions) once separated (Zotz et al., 2000). However, it is not unexpected that bulbils would display an inherently high desiccation tolerance. Any dispersal agent functioning in a xeric habitat should be under strong selection for desiccation tolerance.
Moss spore production ranges from 100 million to tens of billions per square meter of moss cover annually, and any spore potentially traversing hundreds to thousands of kilometers before settling (Miles and Longton, 1992). Moss persistence would indicate a highly plastic capacity for desiccation tolerance or an inherent desiccation tolerance across vulnerable life history phases, assuming costs for maintaining a rapid plastic response are low and/or only expressed in the appropriate environments (Pigliucci, 2005). As spores have high dispersal capacity yet lack a method to control the location of deposition, 


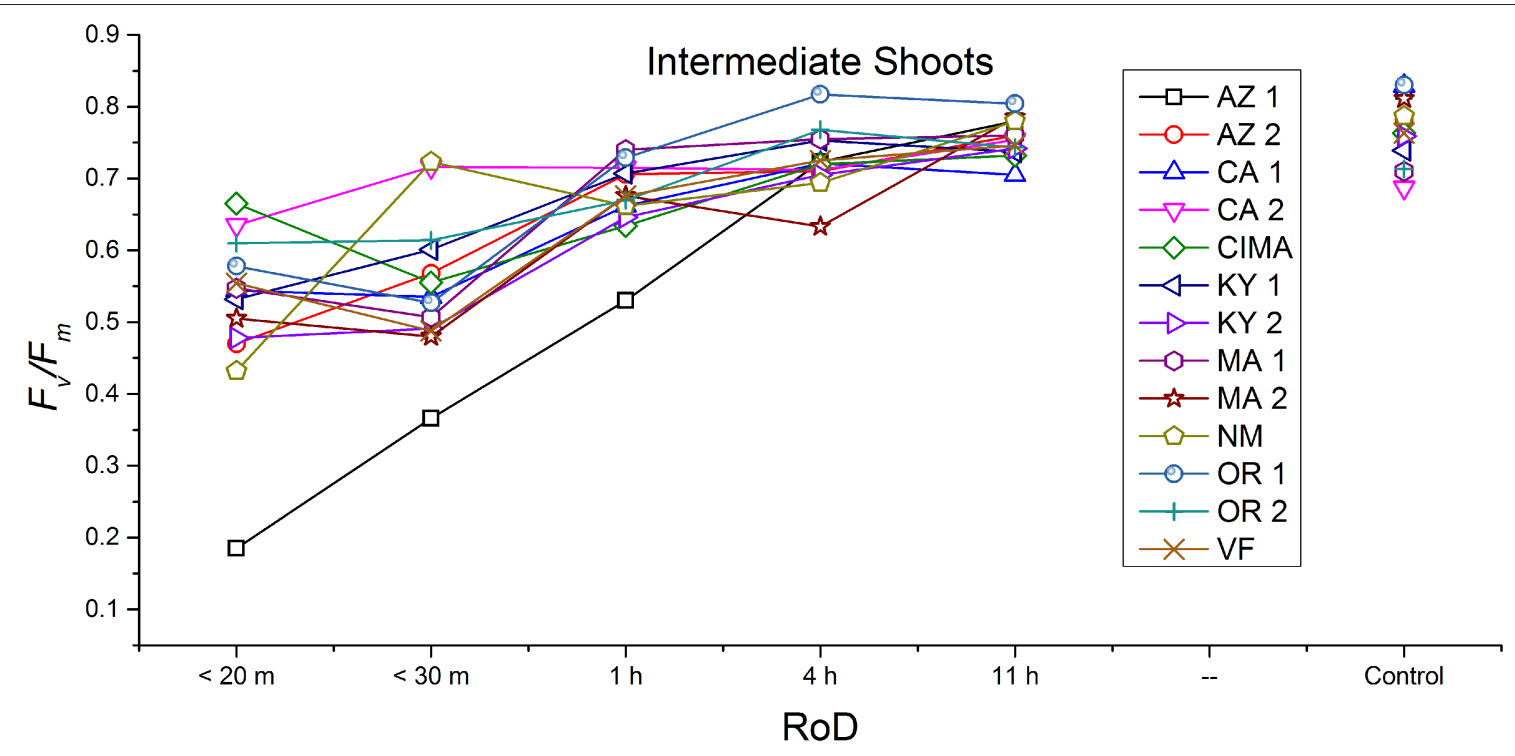

FIGURE 6 | Reaction norms for intermediate shoots from 13 ecotypes exposed to five rates of drying (RoD) $24 \mathrm{~h}$ post rehydration.

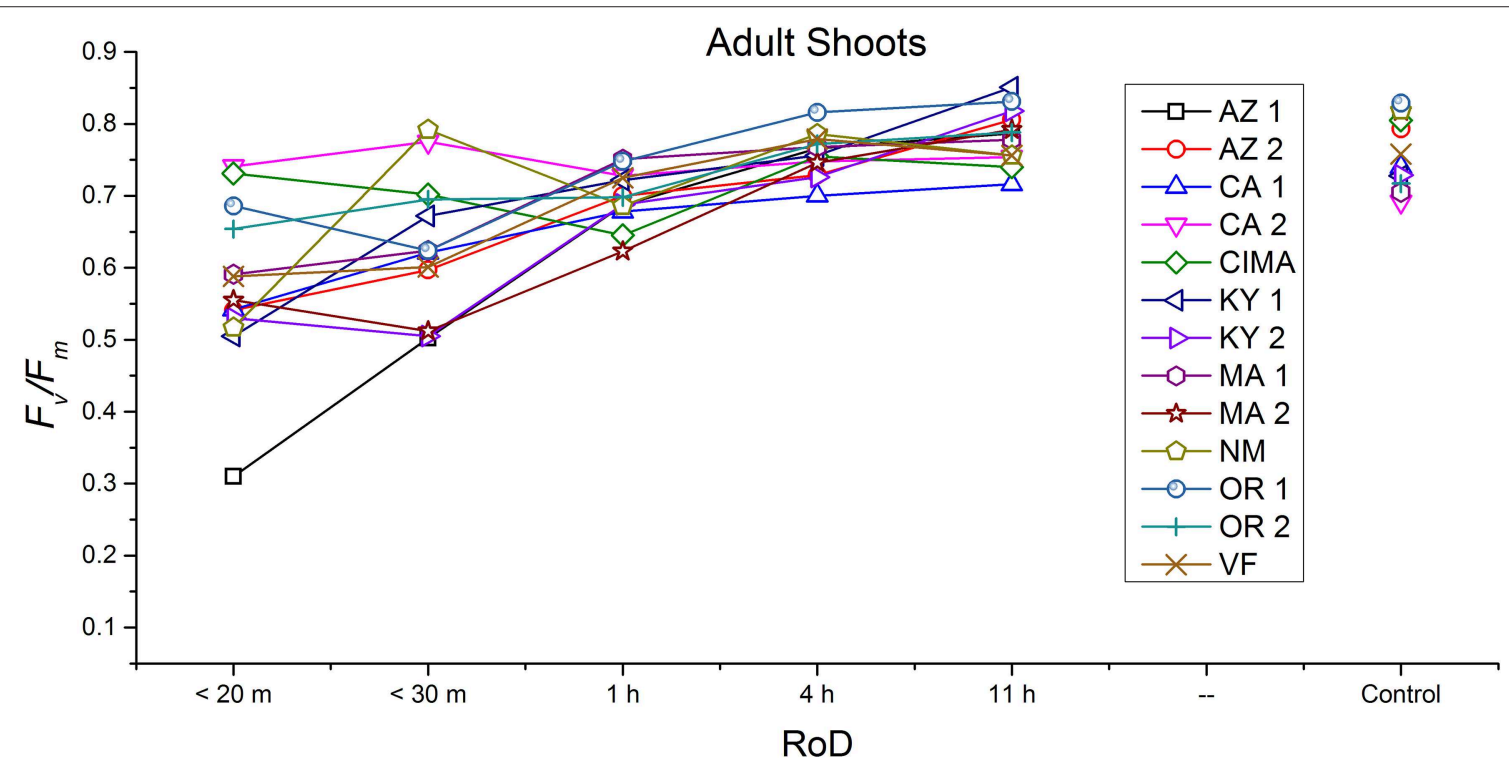

FIGURE 7 | Reaction norms for adult shoots from 13 ecotypes exposed to five rates of drying (RoD) $24 \mathrm{~h}$ post rehydration.

research has long suggested mosses act in accordance with the Baas Becking hypothesis "Everything is everywhere, but the environment selects" (Baas Becking, 1934). This agrees with studies of the genetic structure of moss populations, which have shown high genetic diversity (Skotnicki et al., 1998). An alternative explanation is that high levels of phenotypic plasticity have been selected for in high dispersal species, rendering environmental selection and ecotypic variation to a specific habitat a moot point (Pigliucci, 2005). Aspects supporting high phenotypic plasticity include the wide range of habitats inhabited by $B$. argenteum and its cosmopolitan distribution (Shaw et al., 1989).

Our results suggest that adults and established colonies are more resistant to the effects of altered rainfall patterns that are hypothesized in climate change models due to the high capacity for desiccation tolerance in adult tissue when given short drying times. However, over longer time frames (i.e., years to decades) in xeric habitats or under increasingly xeric conditions, establishment rates of new colonies or expansion of existing colonies could decrease. 


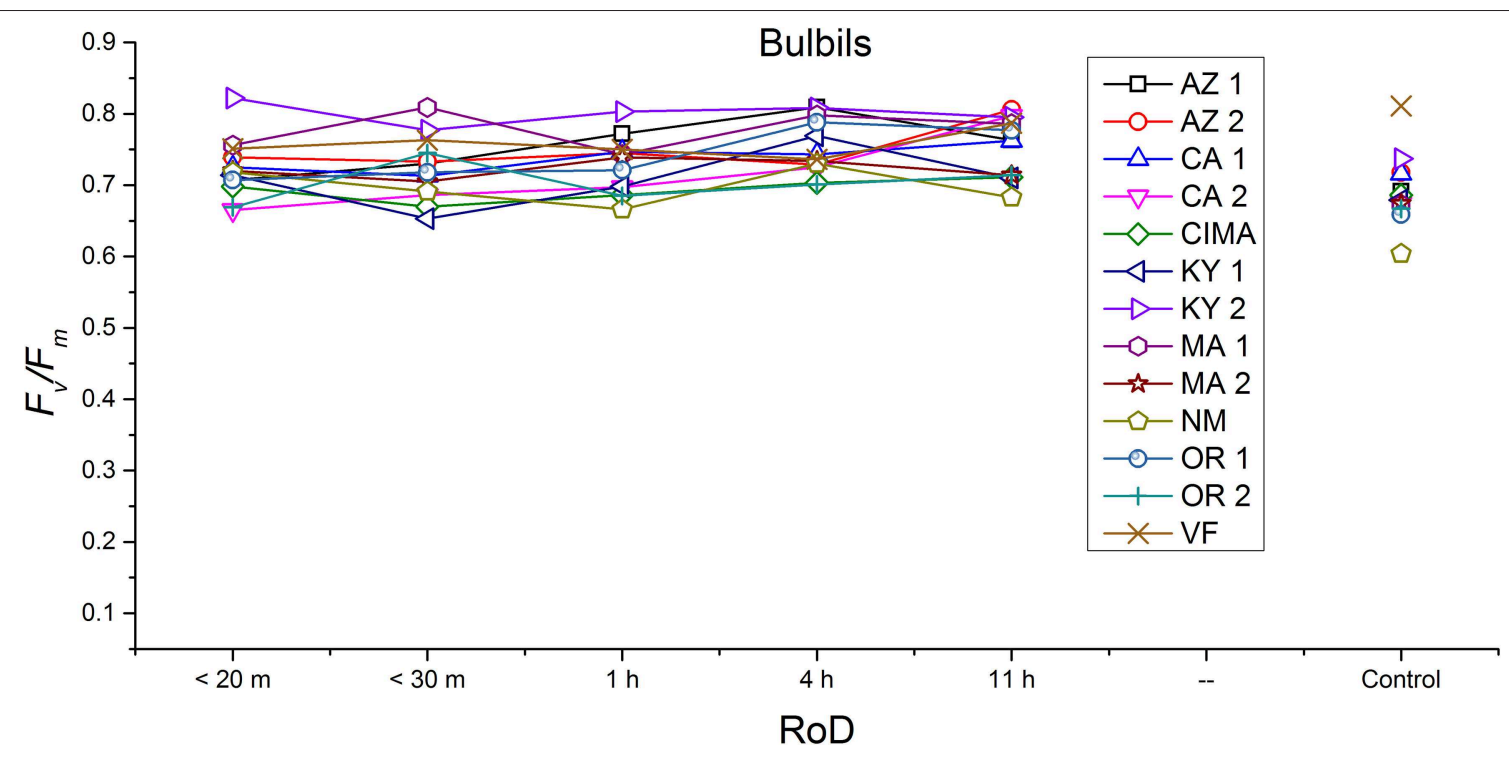

FIGURE 8 | Reaction norms for bulbils from 13 ecotypes exposed to five rates of drying (RoD) $24 \mathrm{~h}$ post rehydration.

Ladrón de Guevara et al. (2018) observed over an 8-year study that moss presence and abundance increased with warming through time, although growth rate reduced over time and the overall impact on the biocrust community was negative.

Our results also suggest that patch establishment and expanding regions of growth of a patch are sensitive to environmental conditions. Establishment or new growth of $B$. argenteum under xeric conditions appears strongly limited by the ability of protonema and juvenile shoots to survive drying. Because protonemal and juvenile tissue show greater sensitivity to rapid desiccation, patch establishment and expansion would likely only occur during wet seasons or favorable years and patches would likely decline under unfavorable conditions. If the rate of successful colony establishment falls beneath the rate at which mature colonies are lost, the cumulative effects would result in either expatriation from localities transitioning to more xeric habitats or a strong selective pressure resulting in increased tolerance across many populations. In general, for mosses, slow drying results in a altered protein profiles during both dehydration and rehydration and greater survival after a desiccation-rehydration cycle (Bewley, 1995; Cruz de Carvalho et al., 2011, 2014), while rapid drying leads to chlorosis and damaged photosynthetic machinery, increased reactive oxygen species production, and protein leakage all of which could be causative mechanisms behind the damage observed (Schonbeck and Bewley, 1981; Cruz de Carvalho et al., 2012, 2014; Stark et al., 2013). The diversity of inherent desiccation tolerance exhibited by $B$. argenteum, as well as plasticity of response to rates of drying, suggest $B$. argenteum might respond to selective pressures resulting in greater or accelerated selection of tolerant phenotypes (Carlson et al., 2014).
During development, mosses might transition from a plastic form of desiccation tolerance to an inherent protection, reducing the time required for inducible desiccation tolerance (Stark and Brinda, 2015; Stark et al., 2016). Bryum argenteum has previously displayed an ability to quickly respond to a changing environment (e.g., Raudenbush et al., 2018). Evolution selects for phenotypic traits in a population that improve the odds of survival and reproduction across life phases while minimizing expenditures. Desiccation tolerance likely has associated energy costs; therefore, it is expected that desiccation tolerance is regulated over development to reduce energy expenditure while maximizing fitness (Stearns, 1989). Factors that guide the expression of traits are the efficient utilization of limited energy resources, habitat or ecosystem conditions, genetic inheritance from ancestors, the ability to deal with stress at various life history phases, or a combination of these factors. We would expect that organisms will invest greater energy toward desiccation tolerance in habitats subjected to desiccation. However, if rates of gene flow with organisms from mesic habitats are high this might not hold true.

The reaction norms displayed by the 13 ecotypes showed a substantial degree of variation in phenotypic plasticity for protonemal and juvenile phases. The variation at these stages likely reflects increased competition during colony initiation and along the expanding edge of established colonies. In mesic habitats, energy expenditure toward a desiccation tolerant phenotype would provide little advantage, but the more rapid establishment of a colony (and the slowed water loss associated with cushion dynamics) and more rapid transition from a juvenile to an adult phase due to rapid growth would provide advantages. In habitats more likely to experience rapid and extreme drying events, any advantage gained from rapid growth at the cost of desiccation tolerance would be easily offset by the 
occurrence of a single unexpected rapid drying event, favoring rapidly inducible phenotypic plasticity as seen in some ecotypes.

\section{Conservation and Selection of Materials for Restoration}

The results of this work provide an experimental framework for both conservation and restoration activities of degraded ecosystems. An ecotype specifically adapted to an environment and more sensitive to changes in a precipitation regime could perish if the home locality experienced long-term change in rainfall patterns that alter tissue drying rates below survivable levels. As a result, the important roles which mosses play in environments are likely threatened, particularly in ecosystems in which mosses contribute to significant ecological functions (e.g., Barros and Field, 2014). Understanding the degree of desiccation tolerance (plastic and inherent) and predicting how mosses will respond to climate change by assessing vulnerability help to predict which ecosystems or populations are most vulnerable. Few studies have evaluated the capacity of moss biocrusts to respond to changes in climate (e.g., Delgado-Baquerizo et al., 2016). One notable example is Robinson et al. (2018) which found a shift in the community composition of Eastern Antarctic mosses toward species which are more desiccation tolerant over a 10-year period from 2008 to 2018. Our results suggest that some moss populations are likely more vulnerable to altered rainfall patterns than others. Previous work has also suggested the vulnerability of existing moss populations (Stark et al., 2011; Reed et al., 2012). This experimental framework could assist land managers to identify vulnerable populations and identify populations within landscapes that can be used for mitigation or restoration actions, such as selection of ecotypes for cultivation and transplantation.

Because non-climate related anthropogenic effects (e.g., habitat destruction and fragmentation) are already damaging many moss populations, resources and guidance are necessary to offset degradation through restoration. Some moss species are cultivated easily in a laboratory (e.g., Greenwood and Stark, 2014; Cruz de Carvalho et al., 2018). There are several studies examining how to improve cultivation (e.g., $\mathrm{Xu}$ et al., 2008; Antoninka et al., 2015; Cruz de Carvalho et al., 2018). Antoninka et al. (2015) observed a 6-fold increase in 4 months of biocrust material containing mosses providing a valuable tool for outplanting. Field studies are limited but studies from desert ecosystems in China suggest mosses can be used as a component for soil stabilization and restoration (e.g., Bu et al., 2013). Utilizing mosses in biocrust restoration in cool deserts is being investigated (Antoninka et al., 2015, 2018), but few studies have used mosses in restoration applications particularly in warm deserts (e.g., Chiquoine et al., 2016; Mojave Desert, North America). Most biocrust restoration work has focused thus far on an algal or cyanobacteria components (e.g., Bu et al., 2013). To the authors' knowledge as of this writing, no published study in warm arid or semiarid ecosystems has incorporated laboratory-cultivated mosses in field studies or restoration efforts.

Selecting ecotypes for cultivation and transplantation that show a high capacity for desiccation tolerance in protonema and juvenile shoots when raised in culture could increase outplanting success of moss material. To increase successful incorporation of mosses into field applications, we suggest the following three strategies to improve outplanting attempts. First, we recommend cultivation to continue until shoots and colonies are fully mature before outplanting; second, harden samples with a slow drying event before outplanting to increase the plastic capacity for desiccation tolerance; and third, limit outplanting to cooler, wetter seasons, as this allows an entire season for new growth and adaptation to the local climate before desiccation stresses are encountered.

Further, we recommend that future restoration studies in aridlands consider the desiccation tolerance capacity of moss ecotypes used for cultivation and later re-introduction. Selection of a rapidly cultivated ecotype is tempting. However, the ability to survive transplanting and reduce field mortality rates should be a higher priority. A simple pilot study before the main effort of cultivation is begun should be employed to select for a balance of growth rate and desiccation tolerance leading to more successful re-introduction rates over the long term.

\section{CONCLUSION}

This study presents a pattern of ecotypic reaction norms to desiccation along a developmental trajectory. The use of two tissues with specialized adaptive roles (i.e., bulbils, protonema), as well as shoot tissue across multiple developmental phases, presents how an entire vegetative life cycle responds to desiccation. We examined not just whether the organism is desiccation tolerant, but also how different life history phases and tissue types prioritize rapid-to-slow induction times to achieve desiccation tolerance. We observed a gradient of responses, thereby allowing predictions of how organisms may respond to future desiccation challenges across life history phases under a variety of scenarios. An extrapolation of our results suggests that we should expect few short-term effects due to high desiccation tolerance of adult shoots, but significant adverse long-term effects on colony establishment due to low tolerance of protonema and juvenile shoots. If these trends hold true for mosses in general, species with reduced dispersal capacity in stressed ecosystems could prove disastrous. In the future, we hope results from this study will contribute to other disciplines, including ecological restoration and land management.

The overall plasticity shown for $B$. argenteum is encouraging and displays greater variation than expected, especially given only 13 ecotypes were examined. The plastic variation in response, current wide species distribution, both geographic as well as habitat variety, ease of long-distance dispersal (via spores) and short distance dispersal (spores and bulbils) suggest that the species may be better poised to respond to climate change than most (Kopp and Matuszewski, 2014). The observed variation in response among tissue types may indicate that the associated benefits of plasticity will also give $B$. argenteum a strong advantage against other species in colonizing new habitats formed by climate change, potentially allowing it to outcompete more narrowly restricted species of mosses both in terms of geographic range and suitable habitats. A quickly dispersing species such as $B$. argenteum could rapidly fill new niches as they appear, acting as a highly invasive organism and 
excluding more slowly dispersing species by occupying these niches, further accelerating the loss of more vulnerable species as they are outcompeted.

\section{DATA AVAILABILITY STATEMENT}

The datasets generated for this study are available on request to the corresponding author.

\section{AUTHOR CONTRIBUTIONS}

JG developed and conducted this study, analyzed the data, and primarily wrote the manuscript. LS aided in experimental design

\section{REFERENCES}

Antoninka, A., Bowker, M. A., Chuckranm, P., Barger, N. N., Reed, S., and Belnap, J. (2018). Maximizing establishment and survivorship of field-collected and greenhouse-cultivated biocrusts in a semi-cold desert. Plant Soil 429, 213-225. doi: 10.1007/s11104-017-3300-3

Antoninka, A., Bowker, M. A., Reed, S. C., and Doherty, K. (2015). Production of greenhouse-grown biocrust mosses and associated cyanobacteria to rehabilitate dryland soil function. Restor. Ecol. 24, 324-335. doi: 10.1111/rec.12311

Baas Becking, L. G. M. (1934). Geobiologie of Inleiding tot de Milieukunde. The Hague: W.P. Van Stockum \& Zoon.

Barros, V. R., and Field, C. B. (2014). Climate Change 2014: Impacts, Adaptation, and Vulnerability. Part B: Regional Aspects. Working Group II Contribution to the IPCC Fifth Assessment Report. Cambridge University Press. doi: 10.1017/СВО9781107415386

Bazzaz, F. A., Chiariello, N. R., Coley, P. D., and Pitelka, L. F. (1987). Allocating resources to reproduction and defense. Bioscience 37, 58-67. doi: $10.2307 / 1310178$

Belnap, J. (2006). The potential roles of biological soil crust in dryland hydrologic cycles. Hydrol. Process. 20, 3159-3178. doi: 10.1002/hyp.6325

Bewley, J. D. (1995). Physiological aspects of desiccation tolerance-a retrospect. Int J. Plant Sci. 156, 393-403. doi: 10.1086/297261

Brown, D. H., and Bates, J. W. (1990). Bryophytes and nutrient cycling. Bio. J. Linn. Soc. 104, 129-147. doi: 10.1111/j.1095-8339.1990.tb02215.x

$\mathrm{Bu}, \mathrm{C} ., \mathrm{Wu}, \mathrm{S}$., Xie, Y., and Zhang, X. (2013). The study of biological soil crusts: hotspots and prospects. Clean-Soil Air Water 41, 899-906. doi: $10.1002 /$ clen.201100675

Buryová, B., and Shaw, A. J. (2005). Phenotypic plasticity in Philonotis fontana (Bryopsida: Bartramiaceae). J. Bryol. 27, 13-22. doi: 10.1179/174328205X40545

Carlson, S. M., Cunningham, C. J., and Westley, P. A. (2014). Evolutionary rescue in a changing world. Trends Ecol. Evol. 29, 521-530. doi: 10.1016/j.tree.2014.06.005

Chaudhary, V. B., Bowker, M. A., O’Dell, T. E., Grace, J. B., Redman, A. E., Rilig, M. C., et al. (2009). Untangling the biological contributions to soil stability in semiarid shurblands. Ecol. Appl. 19, 110-122. doi: 10.1890/07-2076.1

Chiquoine, L. P., Abella, S. R., and Bowker, M. A. (2016). Rapidly restoring biological soil crusts and ecosystem functions in a severely disturbed desert ecosystem. Ecol. Appl. 26, 1260-1272. doi: 10.1002/15-0973

Condon, L. A., and David, A. P. (2016). Filling the interspace-restoring arid land mosses: source populations, organic matter, and overwintering govern success. Ecol. Evol. 6, 7623-7632. doi: 10.1002/ece3.2448

Cruz de Carvalho, R., Bernades da Silva, A., Soares, R., Almeida, A. M., Coelho, A. V., Marques Da Silva, J., et al. (2014). Differential proteomics of dehydration and rehydration in bryophytes: evidence towards a common desiccation tolerance mechanism. Plant Cell Environ. 37, 1499-1515. doi: $10.1111 /$ pce. 12266

Cruz de Carvalho, R., Branquinho, C., and Da Silva, J. M. (2011). Physiological consequences of desiccation in the aquatic bryophyte Fontinalis antipyretica. Planta 234, 195-205. doi: 10.1007/s00425-011-1388-x and editing of manuscript. LC aided in writing and editing of manuscript.

\section{FUNDING}

The publication fees for this article were supported by the UNLV University Libraries Open Article Fund.

\section{SUPPLEMENTARY MATERIAL}

The Supplementary Material for this article can be found online at: https://www.frontiersin.org/articles/10.3389/fevo. 2019.00388/full\#supplementary-material

Cruz de Carvalho, R., Catalá, M., Marques da Silva, J., Branquinho, C., and Barreno, E. (2012). The impact of dehydration rate on the production and cellular location of reactive oxygen species in an aquatic moss. Ann. Bot. 110, 1007-1016. doi: 10.1093/aob/mcs180

Cruz de Carvalho, R., dos Santos, P., and Branquinho, C. (2018). Production of moss-dominated biocrusts to enhance the stability and function of the margins of artificial water bodies. Restor. Ecol. 26, 419-421. doi: 10.1111/rec.12688

Delgado-Baquerizo, M., Maestre, F. T., Reich, P. B., Jeffries, T. C., Gaitan, J. J., Encinar, D., et al. (2016). Microbial diversity drives multifunctionality in terrestrial ecosystems. Nat. Commun. 7:10541. doi: 10.1038/ncomms10541

DeWitt, T. J., Sih, A., and Wilson, D. S. (1998). Costs and limits of phenotypic plasticity. Trends Ecol. Evol. 13, 77-81. doi: 10.1016/S0169-5347(97) 01274-3

Flora of North America Editorial Committee (2014). Flora of North America, Bryophytes: Mosses, Part 2, Vol. 28. Oxford: Flora of North America Editorial Committee.

Gao, B., Zhang, D., Li, X., Yang, H., Zhang, Y., and Wood, A. J. (2015). De novo transcriptome characterization and gene expression profiling of the desiccation tolerant moss Bryum argenteum following rehydration. BMC Genomics 16:1. doi: 10.1186/s12864-015-1633-y

Genty, B., Briantais, J. M., and Baker, N. R. (1989). The relationship between the quantum yield of photosynthetic electron transport and quenching of chlorophyll fluorescence. Biochim. Biophys. Acta. 990, 87-92. doi: 10.1016/S0304-4165(89)80016-9

Ghalambor, C. K., McKay, J. K., Carroll, S. P., and Reznick, D. N. (2007). Adaptive versus non-adaptive phenotypic plasticity and the potential for contemporary adaptation in new environments. Funct. Ecol. 21, 394-407. doi: 10.1111/j.1365-2435.2007.01283.x

Greenwood, J. L., and Stark, L. R. (2014). The rate of drying determines the extent of desiccation tolerance in Physcomitrella patens. Funct. Plant. Biol. 41, 460-467. doi: 10.1071/FP13257

Hassel, K., Pedersen, B., and Söderström, L. (2005). Changes in life-history traits in an expanding moss species: phenotypic plasticity or genetic differentiation? A reciprocal transplantation experiment with Pogonatum dentatum. Ecography 28, 71-80. doi: 10.1111/j.0906-7590.2005.03910.x

He, X., He, K. S., and Hyvönen, J. (2016). Will bryophytes survive in a warming world? Perspect. Plant Ecol. Evol. Syst. 19, 49-60. doi: 10.1016/j.ppees.2016.02.005

Hoagland, D. R., and Arnon, D. I. (1950). The Water-culture Method for Growing Plants Without Soil, 2nd Edn. California: Circular California Agricultural Experiment Station.

Kopp, M., and Matuszewski, S. (2014). Rapid evolution of quantitative traits: theoretical perspectives. Evol. Appl. 7, 169-191. doi: 10.1111/eva.12127

La Farge, C., William, K. H., and England, J. H. (2013). Regeneration of Little Ice Age bryophytes emerging from a polar glacier with implications of totipotency in extreme environments. Proc. Natl. Acad. Sci. U.S.A. 110, 9839-9844. doi: 10.1073/pnas.1304199110

Ladrón de Guevara, M., Gozalo, B., Raggio, J., Lafuente, A., Prieto, M., and Maestre, F. T. (2018). Warming reduces the cover, richness and evenness of 
lichen-dominated biocrusts but promotes moss growth: insights from an $8 \mathrm{yr}$ experiment. New Phytol. 220, 811-823. doi: 10.1111/nph.15000

Matesanz, S., Gianoli, E., and Valladares, F. (2010). Global change and the evolution of phenotypic plasticity in plants. Ann. N. Y. Acad. Sci. 1206: 35-55. doi: 10.1111/j.1749-6632.2010.05704.x

Mediavilla, S., and Escudero, A. (2004). Stomatal responses to drought of mature trees and seedlings of two co-occurring Mediterranean oaks. Forest Ecol. Manag. 187, 281-294. doi: 10.1016/j.foreco.2003.07.006

Miles, C. J., and Longton, R. E. (1992). Deposition of moss spores in relation to distance from parent gametophytes. J. Bryol. 17, 355-368. doi: 10.1179/jbr.1992.17.2.355

Patiño, J., and Vanderpoorten, A. (2018). Bryophyte biogeography. Crit. Rev. Plant Sci. 37, 175-209. doi: 10.1080/07352689.2018.1482444

Pigliucci, M. (2005). Evolution of phenotypic plasticity: where are we going now? Trends Ecol. Evol. 20, 481-486. doi: 10.1016/j.tree.2005.06.001

Proctor, M. C., Oliver, M. J., Wood, A. J., Alpert, P., Stark, L. R., Cleavitt, N. L., et al. (2007). Desiccation-tolerance in bryophytes: a review. Bryologist 110,.595-621. doi: 10.1639/0007-2745(2007)110[595:DIBAR]2.0.CO;2

Raudenbush, Z., Greenwood, J. L., McLetchie, D. N., Eppley, S. M., Keeley, S. J., Castetter, R. C., et al. (2018). Divergence in life-history and developmental traits in silvery-thread moss (Bryum argenteum Hedw.) genotypes between golf course putting greens and native habitats. Weed Sci. 66, 642-650. doi: $10.1017 /$ wsc. 2018.37

Reed, S. C., Coe, K. K., Sparks, J. P., Housman, D. C., Zelikova, T. J., and Belnap, J. (2012). Changes to dryland rainfall result in rapid moss mortality and altered soil fertility. Nat. Clim. Change. 2, 752-755. doi: 10.1038/nclimate1596

Rincon, E., and Grime, J. P. (1989). Plasticity and light interception by six bryophytes of contrasted ecology. J. Ecol. 77, 439-446. doi: 10.2307/2260760

Roads, E., Longton, R. E., and Convey, P. (2014). Millennial timescale regeneration in a moss from Antarctica. Curr. Biol. 24, R222-R223. doi: 10.1016/j.cub.2014.01.053

Robinson, S. A., King, D. H., Bramley-Alves, J., Waterman, M. J., Ashcroft, M. B., Wasley, J., et al. (2018). Rapid change in East Antarctic terrestrial vegetation in response to regional drying. Nat. Clim. Change 8, 879-884. doi: 10.1038/s41558-018-0280-0

Schonbeck, M. W., and Bewley,. J. D. (1981). Responses of the moss Tortula ruralis to desiccation treatments. I. Effects of minimum water content and rates of dehydration and rehydration. Can. J. Bot. 59, 2698-2706. doi: 10.1139/ b81-320

Schreiber, U. B. W. N., Bilger, W., and Neubauer, C. (1995). "Chlorophyll fluorescence as a nonintrusive indicator for rapid assessment of in vivo photosynthesis," in Ecophysiology of Photosynthesis, eds E. D. Schulze and M. M. Caldwell (Heidelberg: Springer Berlin), 49-70. doi: 10.1007/978-3-642-79354-7_3

Shaw, J., Beer, S. C., and Lutz, J. (1989). Potential for the evolution of heavy metal tolerance in Bryum argenteum, a moss. I. Variation within and among populations. Bryologist 72, 73-80. doi: 10.2307/3244019

Shaw, R. G., and Etterson, J. R. (2012). Rapid climate change and the rate of adaptation: insight from experimental quantitative genetics. New Phytol. 195, 752-765. doi: 10.1111/j.1469-8137.2012.04230.x

Skotnicki, M. L., Selkirk, P. M., and Ninham, J. A. (1998). RAPD analysis of genetic variation and dispersal of the moss Bryum pseudotriquetrum from Southern Victoria Land, Antarctica. Polar Biol. 20, 121-126. doi: 10.1007/s003000050285

Stark, L. R. (2017). Ecology of desiccation tolerance in bryophytes: a conceptual framework and methodology. Bryologist 120, 130-165. doi: $10.1639 / 0007-2745-120.2 .130$

Stark, L. R., and Brinda, J. C. (2015). Developing sporophytes transition from an inducible to a constitutive ecological strategy of desiccation tolerance in the moss Aloina ambigua: effects of desiccation on fitness. Ann. Bot. 115, 593-603. doi: $10.1093 / \mathrm{aob} / \mathrm{mcu} 252$

Stark, L. R., Brinda, J. C., and McLetchie, D. N. (2011). Effects of increased summer precipitation and $\mathrm{N}$ deposition on Mojave Desert populations of the biological crust moss Syntrichia caninervis. J. Arid. Environ. 75, pp.457-463. doi: 10.1016/j.jaridenv.2010.12.015
Stark, L. R., Greenwood, J. L., and Brinda, J. C. (2016). Desiccated Syntrichia ruralis shoots regenerate after 20 years in the herbarium. J. Bryol. 38, 1-9. doi: 10.1080/03736687.2016.1176307

Stark, L. R., Greenwood, J. L., Brinda, J. C., and Oliver, M. J. (2013). The desert moss Pterygoneurum lamellatum (Pottiaceae) exhibits an inducible ecological strategy of desiccation tolerance: effects of rate of drying on shoot damage and regeneration. Am. J. Bot. 100, 1522-1531. doi: 10.3732/ajb. 1200648

Stark, L. R., Greenwood, J. L., Brinda, J. C., and Oliver, M. J. (2014). Physiological history may mask the inherent inducible desiccation tolerance strategy of the desert moss Crossidium crassinerve. Plant Biol. 16, 935-946. doi: $10.1111 /$ plb.12140

Stark, L. R., McLetchie, D. N., and Eppley, S. M. (2010). Sex ratios and the shy male hypothesis in the moss Bryum argenteum (Bryaceae). Bryologist 113, 788-797. doi: 10.1639/0007-2745-113.4.788

Stark, L. R., McLetchie, D. N., and Roberts, S. P. (2009). Gender differences and a new adult eukaryotic record for upper thermal tolerance in the desert moss Syntrichia caninervis. J. Therm. Biol. 34, 131-137. doi: $10.1016 /$ j.jtherbio.2008.12.001

Stearns, S. C. (1989). Trade-offs in life-history evolution. Funct. Ecol. 3, 259-268. doi: $10.2307 / 2389364$

Tuba, Z., Slack, N., and Stark, L. R. (2011). Bryophyte Ecology and Climate Change. Cambridge: Cambridge University Press.

Valladares, F., Gianoli, E., and Gómez, J. M. (2007). Ecological limits to plant phenotypic plasticity. New Phytol. 176, 749-763. doi: 10.1111/j.1469-8137.2007.02275.x

Vanderpoorten, A., Patiño, J., Désamoré, A., Laenen, B., Górski, P., Papp, B., et al. (2019). To what extent are bryophytes efficient dispersers? J. Ecol. 107, 2149-2154. doi: 10.1111/1365-2745.13161

Weber, B., Wu, D., Tamm, A., Ruckteschler, N., Rodríguez-Caballero, E., Steinkamp, J., et al. (2015). Biological soil crusts accelerate the nitrogen cycle through large NO and HONO emissions in drylands. Proc. Natl. Acad. Sci. U.S.A. 112, 15384-15389. doi: 10.1073/pnas.1515818112

Werner, O., Espin, R. M. R., Bopp, M., and Atzorn, R. (1991). Abscisic-acidinduced drought tolerance in Funaria hygrometrica Hedw. Planta 186, 99-103. doi: $10.1007 /$ BF00201503

Wood, A. J. (2007). The nature and distribution of vegetative desiccation-tolerance in hornworts, liverworts and mosses. Bryologist 110, 163-177. doi: 10.1639/ 0007-2745(2007)110[163:IENFIB]2.0.CO;2

Xu, S., Yin, C., He, M., and Wang, Y. (2008). A technology for rapid reconstruction of moss-dominated soil crusts. Environ. Eng. Sci. 25, 1129-1138. doi: 10.1089/ees.2006.0272

Zanatta, F., Patiño, J., Lebeau, F., Massinon, M., Hylander, K., de Haan, M., et al. (2016). Measuring spore settling velocity for an improved assessment of dispersal rates in mosses. Ann. Bot. 118, 197-206. doi: 10.1093/aob/mcw092

Zhao, Y., Bowker, M. A., Zhang, Y., and Zaady, E. (2016). "Enhanced recovery of biological soil crusts after disturbance," in Biological Soil Crusts: An Organizing Principle in Drylands, eds B. Weber, B. Büdel, and J. Belnap (Cambridge: Springer), 499-523. doi: 10.1007/978-3-319-30214-0_24

Zotz, G., Schweikert, A., Jetz, W., and Westerman, H. (2000). Water relations and carbon gain are closely related to cushion size in the moss Grimmia pulvinata. New Phytol. 148, 59-67. doi: 10.1046/j.1469-8137.2000.00745.x

Conflict of Interest: The authors declare that the research was conducted in the absence of any commercial or financial relationships that could be construed as a potential conflict of interest.

Copyright (c) 2019 Greenwood, Stark and Chiquoine. This is an open-access article distributed under the terms of the Creative Commons Attribution License (CC BY). The use, distribution or reproduction in other forums is permitted, provided the original author(s) and the copyright owner(s) are credited and that the original publication in this journal is cited, in accordance with accepted academic practice. No use, distribution or reproduction is permitted which does not comply with these terms. 